pag

Business School

WORKING PAPER SERIES

Working Paper

2014-079
Oil prices and MENA stock markets:

New evidence from nonlinear and

asymmetric causalities during and after the crisis period

Ahdi Noomen Ajmi

Ghassen El Montasser

Shawkat Hammoudeh

Duc Khuong Nguyen

http://www.ipag.fr/fr/accueil/la-recherche/publications-WP.html

IPAG Business School

184, Boulevard Saint-Germain

75006 Paris

France 


\title{
Oil prices and MENA stock markets: New evidence from nonlinear and asymmetric causalities during and after the crisis period
}

\author{
Ahdi Noomen Ajmi \\ College of Science and Humanities in Slayel, Salman bin Abdulaziz University, Kingdom of Saudi Arabia \\ ajmi.ahdi.noomen@gmail.com \\ Ghassen El Montasser \\ ESC de Tunis, Manouba University, Tunisia \\ ghassen.el-montasser@laposte.net \\ Shawkat Hammoudeh \\ Lebow College of Business, Drexel University, United States \\ hammousm@drexel.edu \\ Duc Khuong Nguyen \\ IPAG Business School, 184, Boulevard Saint-Germain, 75006 Paris, France \\ duc.nguyen@ipag.fr \\ * Corresponding author
}

\begin{abstract}
This article investigates the potential of nonlinear causal relationships between world oil prices and stock markets in MENA countries during a black swan period that is characterized by rarity and devastating impacts. By using the nonlinear and asymmetric causality test of Kyrtsou and Labys (2006), we mainly find that: $i$ ) oil prices and MENA stock markets interact in a nonlinear manner; $i i)$ the signs of changes in the causing variables are important for detecting the true causality links between the variables; and iii) the nonlinear causality is more pronounced in the case of the Brent than WTI oil prices.
\end{abstract}

Keywords: MENA countries, stock markets, oil prices, nonlinear causality.

JEL Classification: C52, G15, Q43 


\section{Introduction}

The transmission of shocks and volatility across capital markets in several emerging markets and developing countries during episodes of widening economic uncertainties and financial stress such as the global financial crisis of 2007-2009 has garnered considerable interest by the financial community. Policymakers and market authorities in these countries also give heed to the reaction of their capital markets to the unprecedented long swings and sudden surges in international commodity markets, particularly the crude oil markets, over the recent years. Indeed, oil price fluctuations have a direct effect on economic growth, industrial activity, inflation, financial spreads and stock market performance (e.g., Jones and Kaul, 1996; Hamilton, 2003; Lardic and Mignon, 2008; Khalifa et al., 2013). However, changes in oil prices would affect the economic performance of emerging markets economies differently, depending on the degree of their oil dependence, the heterogeneity of their economic structure, the level of their economic and financial markets development and their integration with world economy. The countries in the Middle East and North Africa (MENA) region are among these emerging economies that are particularly sensitive to oil price shocks and they also exhibit important heterogeneities and specificities which need to be analyzed in a robust framework.

The dynamic interactions between oil prices and stock markets have been extensively investigated for many countries but the empirical results are rather conflicting. Broadly speaking, some studies find a negative relationship between oil prices and stock markets, while others document a positive link using more recent datasets. For example, the study of Jones and Kaul (1996) shows that oil price shocks affect significantly and negatively stock prices in Canada and United States through their impacts on real cash flows. This finding is subsequently supported by more recent studies including Sadorsky (1999), Papapetrou (2001) and Ciner (2001), among others. On the other hand, Huang et al. (1996) find evidence against sig- 
nificant relationship between oil prices and the S\&P500 market index. Miller and Ratti (2009) consider stock markets of six OECD countries over the period 1971-2008 and document that the robust negative long-run link between oil price increases and stock market returns disappears after September 1999. Jammazi and Aloui (2010) obtain similar results for three developed markets (France, Japan, and United Kingdom) by combining wavelets and a Markovswitching VAR model. Other studies also conclude in favor of a positive oil-stock market link (El Sharif et al., 2005; Narayan and Narayan, 2010; Ono, 2011).

Several studies have also examined the oil-stock market nexus in emerging and developing countries. The evidence of significant links between oil and stock markets is found in Basher and Sadorsky (2006), Maghyereh and Al-Kandari (2007), and Aloui et al. (2012), among others. It is worth noting that Maghyereh and Al-Kandari (2007) detect significant nonlinear effects of oil prices on stock returns in the Gulf Cooperation Council (GCC) markets. Aloui et al. (2012) adopt the same unconditional and conditional analyses that are used in Basher and Sadorsky (2006), but take the country's oil-dependence profile into account. Other studies find no direct effects or no significant impacts of oil prices on stock markets (e.g., Choi and Hammoudeh, 2006; Hammoudeh and Nandha, 2007; Khalifa et al., 2013). For example, Choi and Hammoudeh (2006) study the responses of five stock markets of the Gulf Cooperation Council (GCC) to the three global factors including the WTI oil spot price index, and find that oil prices changes have no direct effects on these GCC markets. Hammoudeh and Nandha (2007) consider a sample of 15 countries in the Asia-Pacific region, but find that only stock markets in the Philippines and South Korea are sensitive to oil price changes.

The above-mentioned literature shows that not only the oil price risk and the degree of oil dependence matter for emerging and developing stock markets (Driesprong et al., 2008; Aloui et al., 2012), but also the potential of nonlinear relationships between oil and stock markets must be accounted for (Maghyereh and Al-Kandari, 2007; Jawadi et al., 2010). The 
latter issue has however received less attention in the literature, and that the nonlinearity in the oil-stock market relationships can arise when the responses of stock returns to changes in oil prices differ during low and high volatility states of the economy such as booms and recessions. These nonlinear links may also be caused by financial crises, wars, geopolitical tensions, and natural catastrophes which cause breaks in the behavior of oil prices and/or stock prices. In addition, the reaction of stock returns may be asymmetric with respect to positive and negative changes in the price of oil.

The main contribution of this article to the related literature is to investigate the relationship between the world oil prices and the MENA stock markets using the nonlinear and asymmetric causality test of Kyrtsou and Labys (2006) over a period that is wrapped with high uncertainty and financial stress as highlighted by the recent global financial crisis. This test helps to reveal information about the inherent dynamics of the underlying data and pays special attention to the bearing of nonlinearity and asymmetry on the existence of causal relationships among the variables. We consider the two most important oil prices benchmarks (Brent and West Texas Intermediate-WTI), which may have different dynamics and stylized facts, to examine the oil price-MENA market relationships and also to perform the linear Granger causality as the baseline causal model.

Our study is motivated by at least three reasons: $i$ ) the MENA countries encompass the major suppliers of oil in the global energy markets and may reflect uncertainty and sensitivity about the viability of future oil supplies; ii) stock prices in the MENA countries have experienced dramatic changes in their behavior in some periods, particularly during the 2007-2009 financial crises which may lend credibility to an investigation that employs the nonlinear causality approach; and iii) there is actually no such empirical work conducted within the context of the MENA countries using a nonlinear modeling approach. Our results, which provide evidence of nonlinear and asymmetric causal links between oil prices and MENA stock markets, 
are not only useful for policymakers when they embark on adjusting their policies in response to movements in the world crude oil markets, but also because they entail investors to employ nonlinear models for forecasting stock returns to account for changes in oil prices.

The rest of this article is organized as follows. Section 2 presents the empirical method. Section 3 describes the data and discusses the results. Section 4 concludes the article.

\section{Empirical method}

As far as the causal interactions are concerned, the standard (linear) Granger (1969) causality test may be implemented to examine the linear links between two stationary variables. This test stipulates that a time series of $X_{t}$ Granger causes a time series $Y_{t}$ if the past of $X_{t}$ helps to forecast the future of $Y_{t}$ after controlling for the past of $Y_{t}$. In the bivariate case, the linear Granger causality test involves estimating a linear Vector Autoregression (VAR) model of order $k$ and the linear least squares predictors are used to evaluate the predictive power of one time series for another (see, Granger and Newbold, 1986 for more details).

The series $X_{t}$ Granger causes $Y_{t}$ if the parameters associated with the lagged values of $X_{t}$ are jointly significant, while $Y_{t}$ Granger causes $X_{t}$ if the parameters associated with the lagged values of $Y_{t}$ are jointly significant. If both sets of parameters are jointly significant, then there is evidence for a bidirectional relationship between $X_{t}$ and $Y_{t}$.

However, it is widely admitted that economic and financial series may exhibit nonlinear dependencies, particularly during periods of widespread panics and crises. The application of standard Granger causality tests for such series may thus be inadequate. That is why the appropriate point for researchers in this area is to make use of nonlinear causality tests to account for nonlinear dependencies. In this study, we adopt the nonlinear and asymmetric causality test developed by Kyrtsou and Labys (2006), which enables one to reveal interesting information about the inherent dynamics of the underlying oil-stock data-generating processes. Moreover, Hristu-Varsakelis and Kyrtsou (2008) note that the detection of a causality rela- 
tionship does not give information on whether shocks are positive or negative. On the other hand, the absence of an apparent (symmetric) causality link does not exclude the existence of causality when we take into account certain features, such as the nonlinearity and signs of causal effects.

Formally, in order to examine the complex causal relations between the variables $X_{t}$ and $Y_{t}$, Kyrtsou and Labys (2006) introduce the following system of equations, which relies on the bivariate noisy Mackey-Glass (M-G) process introduced by Mackey and Glass (1977):

$$
\begin{aligned}
& X_{t}=\alpha_{11} \frac{X_{t-\tau_{1}}}{1+X_{t-\tau_{1}}^{c_{1}}}-\gamma_{11} X_{t-1}+\alpha_{12} \frac{Y_{t-\tau_{2}}}{1+Y_{t-\tau_{2}}^{c_{2}}}-\gamma_{12} Y_{t-1}+\varepsilon_{t} \\
& Y_{t}=\alpha_{21} \frac{X_{t-\tau_{1}}}{1+X_{t-\tau_{1}}^{c_{1}}}-\gamma_{21} X_{t-1}+\alpha_{22} \frac{Y_{t-\tau_{2}}}{1+Y_{t-\tau_{2}}^{c_{2}}}-\gamma_{22} Y_{t-1}+\vartheta_{t}
\end{aligned}
$$

where $\varepsilon_{t} \rightarrow N(0,1), \vartheta_{t} \rightarrow N(0,1), t=\tau, \ldots ., N$, and $\tau=\max \left(\tau_{1}, \tau_{2}\right) . X_{0}, \ldots, X_{\tau-1}$, and $Y_{0}, \ldots, Y_{\tau-1}$ are the given variables whose relations are likely to be subject to nonlinear causality. The $\alpha_{i j}$ and $\gamma_{i j}$ are parameters to be estimated, $\tau_{i}$ are integer delays, and $c_{i}$ are constants that can be chosen via prior selection. The model (1) can produce various types of dependencies by adjusting the parameters $\tau_{i}$ and $c_{i}$. Fixing these parameters is thus necessary for the M-G model, as changing the delays for example will automatically generate a new relationship between variables. For this, it's necessary to fix these parameters based on information criteria before doing the causality analysis. In this respect, the best delays, $\tau_{1}$ and $\tau_{2}$, are selected a priori on the basis of the likelihood ratio tests and the Schwarz information criterion. This causality test attempts to detect whether past values of a variable $Y_{t}$ have a significant non-linear effect (of the type $\frac{Y_{t-\tau_{2}}}{1+Y_{t-\tau_{2}}^{c_{2}}}$ ) on the current value of another variable $X_{t}$. Model (1) is more appropriate than a simple VAR that is used within the standard (linear) causality framework, particularly when the dependency structures of the time series under consideration are more complicated. Indeed, the M-G-based causality test is similar to the linear Granger causality test, except that 
in the former the models fitted to the series are M-G processes. This test is performed by estimating the M-G model parameters under no constraint using the ordinary least squares. For example, to examine whether $Y$ causes $X$, an $\mathrm{M}-\mathrm{G}$ model is estimated under the constraint $\alpha_{12}=0$ that reflects the null hypothesis. Such a constraint arises from the fact that when $Y$ has a significant nonlinear effect on the current value of $X$ in the M-G model, then $\alpha_{12}$ must be significantly different from zero. Let $\hat{\omega}_{t}$ and $\hat{v}_{t}$ be the residuals obtained by the unconstrained and constrained best-fit M-G models, respectively. Thus, the corresponding sums of the estimated squared residuals can be defined as $S_{u}=\sum_{t=1}^{T} \hat{\omega}_{t}^{2}$ and $S_{c}=\sum_{t=1}^{T} \hat{v}_{t}^{2}$. Recall that $n_{u}=4$ is the number of free parameters in the M-G model, while on the other side $n_{c}=1$ is the number of parameters required to be zero when estimating the restricted model. Obviously, the test statistic $S_{F}$ follows a Fisher distribution as

$$
S_{F}=\frac{\left(S_{c}-S_{u}\right) / n_{c}}{S_{u} /\left(T-n_{u}-1\right)} \rightarrow F\left(n_{c}, T-n_{u}-1\right)
$$

The test presented in equation (2) refers to the symmetric version of the Kyrtsou-Labys causality test between $X$ and $Y$. The asymmetric version of the Kyrtsou-Labys test can be implemented by conditioning for positive or negative values of the causing series. To keep the matters tractable, suppose that we test in Model (1) whether nonnegative returns in the series $X$ cause the series $Y$. In this case, an observation $\left(X_{t}, Y_{t}\right)$ is included in the regression model only if $X_{t-\tau_{1}}>0$. The same restricted set of observations is used to compute the model corresponding to the null hypothesis, i.e., $\alpha_{21}=0$. The procedure is then repeated with the order of the series reversed. While the sign conditioning for the causing series is not the only way to carry out an asymmetric causality, it is often chosen because of its practical relevance. ${ }^{1}$

\footnotetext{
${ }^{1}$ Asymmetric effects may be introduced based on other events such as the start/end of the week and price movement thresholds rather than the non-positivity and non-negativity.
} 


\section{Data and results}

\subsection{Data}

This study examines the causality between world oil prices and real stock returns of eleven MENA countries (Bahrain, Egypt, Jordan, Kuwait, Lebanon, Morocco, Oman, Qatar, Saudi Arabia, Tunisia, and UAE).We use two leading global oil benchmark prices, the West Texas Intermediate Cushing (WTI) and the Europe Brent, which both are quoted in US dollars per barrel, to represent the oil market. Six of the sample countries are oil-based economies (Bahrain, Kuwait, Oman, Qatar, Saudi Arabia, and UAE), and they are either largest importers or exporters of crude oil (Table 1). In terms of market size relative to GDP, Tunisia and Lebanon have the smallest stock markets. They are also the least liquid markets together with Bahrain.

Table 1: Selected indicators of MENA markets over the period 2007-2012

\begin{tabular}{lccccc}
\hline \multicolumn{1}{c}{ Market } & $\begin{array}{c}\text { Number of listed } \\
\text { companies }\end{array}$ & $\begin{array}{c}\text { Market capitaliza- } \\
\text { tion (billion US \$) }\end{array}$ & $\begin{array}{c}\text { Market capitaliza- } \\
\text { tion (\% GDP) }\end{array}$ & $\begin{array}{c}\text { Turnover ra- } \\
\text { tio (\%) }\end{array}$ & $\begin{array}{c}\text { Annual balance of trade in crude } \\
\text { oil (1000 barrels per day) }\end{array}$ \\
\hline Bahrain & 44.66 & 19.982 & 106.42 & 4.66 & -221.908 \\
Egypt & 298.50 & 84.052 & 61.20 & 46.98 & 25.247 \\
Jordan & 257.66 & 32.329 & 163.65 & 36.06 & -75.159 \\
Kuwait & 200.00 & 118.122 & 105.85 & 51.60 & $1,580.267$ \\
Lebanon & 10.33 & 110.728 & 36.62 & 8.28 & 0 \\
Morocco & 75.50 & 64.339 & 79.93 & 25.19 & -113.821 \\
Oman & 121.33 & 19.228 & 37.90 & 25.42 & 658.807 \\
Qatar & 42.83 & 105.838 & 93.37 & 28.89 & 863.888 \\
S. Arabia & 137.83 & 357.647 & 87.14 & 118.02 & $6,840.486$ \\
Tunisia & 53.83 & 83.465 & 18.25 & 16.11 & 67.269 \\
UAE & 98.00 & 81.081 & 38.08 & 78.55 & $2,237.787$ \\
\hline
\end{tabular}

Notes: this table reports the average values of selected indicators for the sample MENA markets. The market capitalization as share of GDP and the annual balance of trade in crude oil (total exports of crude oil minus total imports) is averaged over the period 2007-2010 where data are available. Turnover ratio is measured by the ratio of traded value to the total market capitalization.

Table 2: Summary statistics and results of unit root tests

\begin{tabular}{lcccccccccc}
\hline & \multicolumn{4}{c}{ Descriptive statistics of daily returns } & \multicolumn{3}{c}{ ADF test } & \multicolumn{2}{c}{ PP test } \\
\cline { 2 - 12 } & Mean & Max. & Min. & Skew. & Kurt. & JB & $\begin{array}{c}\text { Price se- } \\
\text { ries }\end{array}$ & $\begin{array}{c}\text { Return } \\
\text { series }\end{array}$ & $\begin{array}{c}\text { Price se- } \\
\text { ries }\end{array}$ & $\begin{array}{c}\text { Return } \\
\text { series }\end{array}$ \\
\hline Bahrain & -0.0014 & 0.0716 & -0.2343 & -4.1001 & 57.3919 & 0.0000 & 0.6999 & 0.0000 & 0.7115 & 0.0000 \\
Egypt & -0.0004 & 0.1045 & -0.1714 & -1.0856 & 11.6730 & 0.0000 & 0.4919 & 0.0000 & 0.5179 & 0.0000 \\
Jordan & -0.0006 & 0.0792 & -0.0975 & -0.8080 & 12.3212 & 0.0000 & 0.7065 & 0.0000 & 0.7189 & 0.0000 \\
Kuwait & -0.0007 & 0.0871 & -1.4957 & -1.4957 & 15.9422 & 0.0000 & 0.4013 & 0.0000 & 0.3924 & 0.0000 \\
Lebanon & -0.0002 & 0.1032 & -0.1018 & 0.8511 & 14.0695 & 0.0000 & 0.7921 & 0.0000 & 0.7531 & 0.0000 \\
Morocco & -0.0004 & 0.0549 & -0.0769 & -0.2913 & 6.4361 & 0.0000 & 0.7934 & 0.0000 & 0.8450 & 0.0000 \\
Oman & -0.0004 & 0.1074 & -0.1733 & -1.9876 & 27.6354 & 0.0000 & 0.7579 & 0.0000 & 0.7443 & 0.0000 \\
Qatar & $-1.05 \times 10^{-5}$ & 0.1125 & -0.1472 & -1.3329 & 19.6894 & 0.0000 & 0.4699 & 0.0000 & 0.4663 & 0.0000 \\
S. Arabia & $-7.40 \times 10^{-5}$ & 0.1034 & -0.2157 & -2.2115 & 30.3467 & 0.0000 & 0.4727 & 0.0000 & 0.4299 & 0.0000 \\
Tunisia & 0.0001 & 0.0904 & -0.0716 & 0.1825 & 9.2932 & 0.0000 & 0.1421 & 0.0000 & 0.1785 & 0.0000 \\
UAE & -0.0008 & 0.1862 & -0.1727 & -0.8974 & 17.1276 & 0.0000 & 0.3396 & 0.0000 & 0.3471 & 0.0000 \\
WTI & $5.68 \times 10^{-5}$ & 0.2127 & -0.1306 & 0.3399 & 8.7549 & 0.0000 & 0.3806 & 0.0000 & 0.4242 & 0.0000 \\
Brent & 0.0002 & 0.1348 & -0.1132 & -0.1165 & 6.3122 & 0.0000 & 0.7664 & 0.0000 & 0.7730 & 0.0000 \\
\hline
\end{tabular}

Notes: Italic values in the table are the p-values for the Jarque-Bera test that examines the null hypothesis of normal distribution, and for the unit root tests that examine the null hypothesis of a unit root. 
Our sample period focuses on and the aftermath of the recent global financial crisis, and thus it ranges from July 2, 2007 to August 27, 2012. The data are obtained from the Bloomberg database and the daily returns are calculated from the daily price data by taking the natural logarithm of the ratio of two successive prices. Table 2 presents the summary statistics of the return series as well as the results of commonly-used unit root tests (ADF and PP) applied to both the price and return series of the two variables. The results of the unit root tests suggest that return series are integrated of order one $I(1)$, and thus suitable for further statistical analysis. The daily stock market return averages are negative, ranging from $-0.007 \%$ (Saudi Arabia) to $-0.11 \%$ (Bahrain), except for Tunisia. The oil market experiences a positive average return for both WTI and Brent, reflecting the increasing trend of oil prices that prevailed during most of the sample period. Skewness is negative for all stock markets, except for Lebanon and Tunisia which, as indicated before, have the smallest market capitalization/GDP ratio and their markets are among the lowest turnover ratios. It is positive for WTI while negative for Brent. The kurtosis values for stock returns are above three for all the series. Finally, the Jarque-Bera test rejects the normality at the $1 \%$ significance level for all the series.

\subsection{Linear Granger causality test}

As baseline estimation, we first examine the linear causal relationships between the oil and each of the eleven MENA stock market returns within the standard Granger causality framework. The results reported in Table 3 show that there is bidirectional causality between the WTI oil and stock market returns for all the MENA countries, except for Egypt and Morocco for which we report a unidirectional causality from the stock market to the WTI oil market in the case of the former and from the WTI oil market to the stock markets in the case of the latter. Egypt is a producer of oil and natural gas, and about three million barrels per day of the world's crude oil exports go through its Suez Canal. Morocco on the other hand is a non-oil producer and its market is closely connected to the European markets. The findings for the 
MENA countries where bidirectional causal effects are found imply that the information contained in the oil price constitutes relevant additional signal for stock prices, and that changes in stock market performance drive significantly the movements of oil prices as well. When the Brent oil price is used, we find evidence of bidirectional causality for all countries, except for Egypt, Lebanon, Oman, and Tunisia where the causality from stock markets to oil market is rejected. Morocco's stock market is only sensitive to the changes in the Brent oil prices.

Table 3: Linear Granger causality results

\begin{tabular}{|c|c|c|c|c|}
\hline & $\begin{array}{r}\mathrm{H}_{0}: \text { Stock market returns } \\
\text { do not cause the Brent } \\
\text { oil returns }\end{array}$ & $\begin{array}{r}\mathrm{H}_{0} \text { : Brent oil returns do } \\
\text { not cause stock market re- } \\
\text { turns }\end{array}$ & $\begin{array}{r}\mathrm{H}_{0}: \text { Stock market returns } \\
\text { do not cause the WTI oil } \\
\text { returns }\end{array}$ & $\begin{array}{r}\mathrm{H}_{0} \text { : The WTI oil returns } \\
\text { do not cause stock market } \\
\text { returns }\end{array}$ \\
\hline Bahrain & $0.0018^{* * *}$ & $0.0002^{\text {***** }}$ & $0.0020^{* * * *}$ & $0.0043^{* * * *}$ \\
\hline Egypt & 0.3875 & $0.0000^{\text {**** }}$ & 0.1261 & $0.0000^{* * * *}$ \\
\hline Jordan & $0.0228^{* *}$ & $0.0000^{* * *}$ & $0.0016^{* * *}$ & $0.0000^{* * *}$ \\
\hline Kuwait & $0.0241^{* *}$ & $0.0000^{\text {**** }}$ & $0.0027^{* * * *}$ & $0.0005^{\text {**** }}$ \\
\hline Lebanon & 0.1659 & $0.0000^{* * * *}$ & $0.0027^{* * * *}$ & $0.0008^{* * *}$ \\
\hline Morocco & $0.0613^{*}$ & $0.0253^{* *}$ & $0.0014^{* * *}$ & 0.2825 \\
\hline Oman & 0.8063 & $0.0000^{\text {***** }}$ & $0.0096^{* * * *}$ & $0.0000^{* * * *}$ \\
\hline Qatar & $0.0040^{\text {**** }}$ & $0.0000^{* * *}$ & $0.0009^{* * *}$ & $0.0000^{* * *}$ \\
\hline S. Arabia & $0.0117^{* *}$ & $0.0000^{\text {**** }}$ & $0.0026^{* * *}$ & $0.0000^{* * * *}$ \\
\hline Tunisia & 0.5560 & $0.0005^{* * *}$ & $0.0688^{*}$ & $0.0178^{* *}$ \\
\hline UAE & $0.0223^{* * *}$ & $0.0000^{\text {**** }}$ & $0.0030^{* * * *}$ & $0.0000^{* * * *}$ \\
\hline
\end{tabular}

Notes: The values in the table are p-values. ${ }^{* * * *},{ }^{* *}$ and ${ }^{*}$ indicate, respectively, significance at the $1 \%, 5 \%$ and $10 \%$ levels.

\subsection{The nonlinear Kyrtsou and Labys (2006) causality test}

The results of the standard (linear) Granger causality test in Table 3 may be spurious if the relationships between the oil prices and MENA stock markets are exposed to nonlinearity which is particularly caused by rare events, sudden changes in demand and supply conditions in the oil markets, and important shocks to stock markets due to crises and widespread panics. Ciner (2001) finds evidence that oil and stock market returns in the United States are connected in a nonlinear manner. The use of the nonlinear and asymmetric Kyrtsou-Labys causality test to gauge the complexity of oil-stock return nexus would thus provide more robust results.

Table 4 reports the results for the prior selection of the parameters of the M-G models which should be estimated before the causal relationships between the oil prices and stock markets can be examined. We note that the integer delays are most of the time equal to one and do not exceed 2 for all the series under consideration. This finding thus reflects the quasiimmediate reaction of the MENA stock market returns to the oil price fluctuations. 
Table 4: Parameter-prior selection in the M-G model

\begin{tabular}{|c|c|c|c|c|c|c|c|c|}
\hline \multirow[t]{2}{*}{ Market } & \multicolumn{4}{|c|}{ WTI crude oil } & \multicolumn{4}{|c|}{ Brent crude oil } \\
\hline & $\tau_{1}$ & $\tau_{2}$ & $c_{1}$ & $c_{2}$ & $\tau_{1}$ & $\tau_{2}$ & $c_{1}$ & $c_{2}$ \\
\hline $\mathrm{SM}_{\mathrm{BAH}}$ & 1 & 1 & 1 & 1 & 1 & 1 & 5 & 1 \\
\hline $\mathrm{SM}_{\mathrm{EGY}}$ & 1 & 1 & 1 & 10 & 1 & 1 & 5 & 10 \\
\hline $\mathrm{SM}_{\mathrm{JOR}}$ & 1 & 1 & 2 & 3 & 1 & 1 & 3 & 3 \\
\hline $\mathrm{SM}_{\mathrm{KUW}}$ & 1 & 1 & 1 & 10 & 1 & 1 & 7 & 1 \\
\hline $\mathrm{SM}_{\mathrm{LEB}}$ & 1 & 1 & 1 & 9 & 1 & 1 & 1 & 9 \\
\hline $\mathrm{SM}_{\mathrm{MOR}}$ & 1 & 1 & 1 & 10 & 1 & 1 & 9 & 10 \\
\hline $\mathrm{SM}_{\mathrm{OMA}}$ & 1 & 1 & 1 & 9 & 1 & 1 & 5 & 2 \\
\hline $\mathrm{SM}_{\mathrm{QAT}}$ & 1 & 1 & 2 & 10 & 1 & 1 & 6 & 10 \\
\hline $\mathrm{SM}_{\mathrm{SA}}$ & 2 & 2 & 2 & 4 & 1 & 1 & 9 & 1 \\
\hline $\mathrm{SM}_{\mathrm{TUN}}$ & 1 & 1 & 2 & 2 & 1 & 1 & 3 & 4 \\
\hline $\mathrm{SM}_{\mathrm{UAE}}$ & 1 & 2 & 1 & 1 & 1 & 1 & 5 & 1 \\
\hline
\end{tabular}

Notes: This table reports the results for the parameter-prior selection. $\tau_{1}$ and $\tau_{2}$ are the optimal integer delay variables for the causality from each of the two oil prices to the corresponding stock market index, and for the causality from the corresponding stock market to each oil price, respectively. The constants $c_{1}$ and $c_{2}$ are the powers of the lagged values of each pair of oil and stock market returns. $S M$ designates stock markets.

Table 5: Nonlinear Kyrtsou-Labys causality test for Brent oil and MENA stock market returns

\begin{tabular}{|c|c|c|c|c|c|c|}
\hline \multirow[b]{2}{*}{ Causality } & \multicolumn{2}{|c|}{ Symmetric case } & \multicolumn{2}{|c|}{ Asymmetric $^{(P)}$ case } & \multicolumn{2}{|c|}{ Asymmetric $^{(\mathrm{N})}$ case } \\
\hline & F-statistic & Probability & F-statistic & Probability & F-statistic & Probability \\
\hline Brent $\rightarrow \mathrm{SM}_{\mathrm{BAH}}$ & $7.1064 * * *$ & 0.0078 & $17.4028^{* * *}$ & 0.0000 & 1.1505 & 0.2837 \\
\hline $\mathrm{SM}_{\mathrm{Bah}} \rightarrow$ Brent & 1.8769 & 0.1709 & $6.3057^{* *}$ & 0.0122 & 0.1859 & 0.6664 \\
\hline Brent $\rightarrow \mathrm{SM}_{\mathrm{EGY}}$ & 0.3913 & 0.5318 & 1.3011 & 0.2542 & 2.0656 & 0.1509 \\
\hline $\mathrm{SM}_{\mathrm{EGY}} \rightarrow$ Brent & 0.1307 & 0.7178 & 0.2043 & 0.6514 & 0.0039 & 0.9501 \\
\hline Brent $\rightarrow \mathrm{SM}_{\mathrm{JOR}}$ & $5.9576^{* *}$ & 0.0148 & $9.3887^{* * *}$ & 0.0022 & 0.1430 & 0.7054 \\
\hline $\mathrm{SM}_{\mathrm{JOR}} \rightarrow$ Brent & $10.0003^{* * *}$ & 0.0016 & $6.2124^{* *}$ & 0.0128 & $9.2049^{* * *}$ & 0.0025 \\
\hline Brent $\rightarrow \mathrm{SM}_{\mathrm{KUW}}$ & $53.9082^{* * *}$ & 0.0000 & $88.0636^{* * *}$ & 0.0000 & $12.8111^{* * *}$ & 0.0003 \\
\hline $\mathrm{SM}_{\mathrm{KUW}} \rightarrow$ Brent & $4.4443^{* *}$ & 0.0352 & $32.2626^{* * *}$ & 0.0000 & 0.1068 & 0.7438 \\
\hline Brent $\rightarrow \mathrm{SM}_{\mathrm{LEB}}$ & $5.3220^{* *}$ & 0.0212 & 1.1109 & 0.2921 & 0.6206 & 0.4310 \\
\hline $\mathrm{SM}_{\mathrm{LEB}} \rightarrow$ Brent & 0.9081 & 0.3408 & 0.0496 & 0.8238 & $4.7202^{* *}$ & 0.0300 \\
\hline $\mathrm{Brent} \rightarrow \mathrm{SM}_{\mathrm{MOR}}$ & $40.4039^{* * *}$ & 0.0000 & $69.3062^{* * *}$ & 0.0000 & 0.8616 & 0.3535 \\
\hline $\mathrm{SM}_{\mathrm{MOR}} \rightarrow$ Brent & $3.1799^{*}$ & 0.0748 & 0.0000 & 1 & $6.1540^{* *}$ & 0.0132 \\
\hline Brent $\rightarrow \mathrm{SM}_{\mathrm{OMA}}$ & $5.5417^{* *}$ & 0.0187 & $8.4627^{* * *}$ & 0.0037 & $24.5948^{* * *}$ & 0.0000 \\
\hline $\mathrm{SM}_{\mathrm{OMA}} \rightarrow$ Brent & $6.2650^{* *}$ & 0.0124 & $22.6798^{* * *}$ & 0.0000 & $6.2330^{* *}$ & 0.0127 \\
\hline Brent $\rightarrow \mathrm{SM}_{\mathrm{OAT}}$ & $12.0760^{* * *}$ & 0.0005 & $27.1064^{\text {***** }}$ & 0.0000 & 0.8355 & 0.3609 \\
\hline $\mathrm{SM}_{\mathrm{QAT}} \rightarrow$ Brent & 0.1393 & 0.7090 & $3.3007^{*}$ & 0.0695 & 0.3780 & 0.5388 \\
\hline Brent $\rightarrow \mathrm{SM}_{\mathrm{SA}}$ & $16.5571^{* * *}$ & 0.0001 & $38.5952^{* * *}$ & 0.0000 & 2.5476 & 0.1107 \\
\hline $\mathrm{SM}_{\mathrm{SA}} \rightarrow$ Brent & 0.6691 & 0.4135 & $5.0048^{* *}$ & 0.0255 & 0.6320 & 0.4268 \\
\hline Brent $\rightarrow \mathrm{SM}_{\mathrm{TUN}}$ & 1.2219 & 0.2692 & $3.4502^{*}$ & 0.0635 & 0.0008 & 0.9769 \\
\hline $\mathrm{SM}_{\mathrm{TUN}} \rightarrow$ Brent & 0.0108 & 0.9172 & 0.0459 & 0.8303 & 0.0001 & 0.9929 \\
\hline Brent $\rightarrow \mathrm{SM}_{\mathrm{UAE}}$ & $11.4971^{* * *}$ & 0.0007 & $23.5639^{* * *}$ & 0.0000 & $15.2557^{* * *}$ & 0.0001 \\
\hline $\mathrm{SM}_{\mathrm{UAE}} \rightarrow$ Brent & 0.9716 & 0.3245 & 1.6395 & 0.2006 & 0.1755 & 0.6753 \\
\hline
\end{tabular}

Notes: we consider the null hypothesis that $A$ does not cause $B$. The asterisks ${ }^{* * *},{ }^{* *}$ and ${ }^{*}$ indicate rejection of the hypothesis of no causality at the $1 \%, 5 \%$ and $10 \%$, respectively. Asymmetric ${ }^{(\mathrm{P})}$ and Asymmetric ${ }^{(\mathrm{N})}$ indicate the asymmetric case for positive and negative changes in the causing variables, respectively. $S M$ designates stock markets.

Regarding the symmetric version of the Kyrtsou-Labys test, we can see from Table 5 that among the eleven countries, there are four showing bidirectional nonlinear causality between Brent and the stock market index (Jordan, Kuwait, Morocco, and Oman). With the exception of Morocco, these are relatively small open countries. For the rest of the countries, there are unidirectional linear causal relationships between the two variables, except for Egypt and Tunisia which have no directional relationships in any direction. It is also noted that there exist unidirectional nonlinear causality relationships running from positive changes in Brent 
to all stock market indices, except for Egypt and Lebanon. On the other hand, the negative changes in Brent cause only the stock market indices of Kuwait, Oman and UAE. An important result worth mentioning is that Egypt does not show any causal relationship between its stock index and Brent whatever the adopted version of the test is.

Table 6: Nonlinear Kyrtsou-Labys causality test for WTI oil and MENA stock market returns

\begin{tabular}{|c|c|c|c|c|c|c|}
\hline \multirow[b]{2}{*}{ Relation $\mathrm{A} \rightarrow \mathrm{B}$} & \multicolumn{2}{|c|}{ Symmetric case } & \multicolumn{2}{|c|}{ Asymmetric ${ }^{(P)}$ case } & \multicolumn{2}{|c|}{ Asymmetric $^{(\mathrm{N})}$ case } \\
\hline & F-statistic & Probability & F-statistic & Probability & F-statistic & Probability \\
\hline $\mathrm{WTI} \rightarrow \mathrm{SM}_{\mathrm{BAH}}$ & $6.4368^{* *}$ & 0.0113 & 1.6392 & 0.2007 & 0.0196 & 0.8886 \\
\hline $\mathrm{SM}_{\mathrm{BAH}} \rightarrow \mathrm{WTI}$ & 2.3360 & 0.1267 & $4.8414^{* *}$ & 0.0280 & 0.1305 & 0.7179 \\
\hline $\mathrm{WTI} \rightarrow \mathrm{SM}_{\mathrm{EGY}}$ & $2.7784^{*}$ & 0.0958 & 0.0067 & 0.9348 & 0.7266 & 0.3941 \\
\hline $\mathrm{SM}_{\mathrm{EGY}} \rightarrow \mathrm{WTI}$ & 0.0697 & 0.7919 & 0.0003 & 0.9850 & 0.7440 & 0.3886 \\
\hline $\mathrm{WTI} \rightarrow \mathrm{SM}_{\mathrm{JOR}}$ & $7.3174^{* * *}$ & 0.0069 & $12.1773^{* * *}$ & 0.0005 & 1.7009 & 0.1924 \\
\hline $\mathrm{SM}_{\mathrm{JOR}} \rightarrow \mathrm{WTI}$ & $10.3024^{* * *}$ & 0.0014 & $3.7514^{*}$ & 0.0530 & $9.7436^{* * *}$ & 0.0018 \\
\hline $\mathrm{WTI} \rightarrow \mathrm{SM}_{\mathrm{KUW}}$ & $4.2807 * *$ & 0.0388 & 0.4713 & 0.4925 & 0.3820 & 0.5366 \\
\hline $\mathrm{SM}_{\mathrm{KUW}} \rightarrow \mathrm{WTI}$ & $7.1622^{* * *}$ & 0.0075 & $17.1555^{* * *}$ & 0.0000 & $14.8150^{* * *}$ & 0.0001 \\
\hline $\mathrm{WTI} \rightarrow \mathrm{SM}_{\mathrm{LEB}}$ & $5.5099^{* *}$ & 0.0191 & 1.0684 & 0.3015 & 0.7714 & 0.3799 \\
\hline $\mathrm{SM}_{\mathrm{LEB}} \rightarrow \mathrm{WTI}$ & 0.0148 & 0.9032 & 0.0945 & 0.7586 & 0.0330 & 0.8558 \\
\hline $\mathrm{WTI} \rightarrow \mathrm{SM}_{\mathrm{MOR}}$ & 2.4949 & 0.1145 & 1.0230 & 0.3120 & $7.1216^{* * *}$ & 0.0077 \\
\hline $\mathrm{SM}_{\mathrm{MOR}} \rightarrow \mathrm{WTI}$ & 0.2748 & 0.6002 & 0.0000 & 1 & 0.2733 & 0.6012 \\
\hline $\mathrm{WTI} \rightarrow \mathrm{SM}_{\mathrm{OMA}}$ & $13.3506^{* * *}$ & 0.0002 & 1.8242 & 0.1771 & $3.7421^{*}$ & 0.0533 \\
\hline $\mathrm{SM}_{\mathrm{OMA}} \rightarrow \mathrm{WTI}$ & 1.5737 & 0.2099 & $20.4367 * * *$ & 0.0000 & 1.4452 & 0.2295 \\
\hline $\mathrm{WTI} \rightarrow \mathrm{SM}_{\mathrm{QAT}}$ & 1.8323 & 0.1761 & $2.9586^{*}$ & 0.0857 & 0.0880 & 0.7668 \\
\hline $\mathrm{SM}_{\mathrm{QAT}} \rightarrow \mathrm{WTI}$ & 0.3000 & 0.5840 & $10.5064^{* * * *}$ & 0.0012 & 1.9765 & 0.1600 \\
\hline $\mathrm{WTI} \rightarrow \mathrm{SM}_{\mathrm{SA}}$ & $19.5339^{* * *}$ & $36.5661^{* * *}$ & $36.5661^{* * *}$ & 0.0000 & $10.0526^{* * *}$ & 0.0016 \\
\hline $\mathrm{SM}_{\mathrm{SA}} \rightarrow \mathrm{WTI}$ & $11.8751^{* * *}$ & $8.2500^{* * *}$ & $8.2500^{* * *}$ & 0.0041 & $12.9532^{* * *}$ & 0.0003 \\
\hline $\mathrm{WTI} \rightarrow \mathrm{SM}_{\mathrm{TUN}}$ & 0.0749 & 0.2487 & 0.2487 & 0.6181 & 0.0825 & 0.7740 \\
\hline $\mathrm{SM}_{\mathrm{TUN}} \rightarrow \mathrm{WTI}$ & 0.0557 & 0.1415 & 0.1415 & 0.7069 & 1.0832 & 0.2982 \\
\hline $\mathrm{WTI} \rightarrow \mathrm{SM}_{\mathrm{UAE}}$ & $4.3173^{* *}$ & 1.3188 & 1.3188 & 0.2510 & 0.0454 & 0.8314 \\
\hline $\mathrm{SM}_{\mathrm{UAE}} \rightarrow \mathrm{WTI}$ & $8.5179^{* * *}$ & 1.2009 & 1.2009 & 0.2734 & 10.9390 & 0.0010 \\
\hline
\end{tabular}

Notes: we consider the null hypothesis that $A$ does not cause $B .{ }^{* * * *},{ }^{* * *}$ and ${ }^{*}$ indicate the rejection of the hypothesis of no causality at the $1 \%, 5 \%$ and $10 \%$, respectively. Asymmetric ${ }^{(\mathrm{P})}$ and Asymmetric ${ }^{(\mathrm{N})}$ indicate asymmetric case for positive and negative changes in the causing variables, respectively.SM designates stock markets.

Table 6 shows that by adopting the symmetric version of the Kyrtsou-Labys test, we can detect bidirectional (symmetric) nonlinear causality relationships between WTI oil and the stock market returns for Jordan, Kuwait, Saudi Arabia, and UAE. We should note here that Jordan was once invited to join the oil rich GCC bloc (Kim and Hammoudeh, 2013). We also record unidirectional (symmetric) nonlinear causal relationships for the rest of the countries, except for Morocco, Qatar and Tunisia. Considering the asymmetric version, positive changes in WTI cause changes in the stock prices in a nonlinear manner for only Jordan, Qatar and Saudi Arabia. As indicated, Jordan is a satellite economy to the GCC countries and benefits from higher prices as the GCC oil producers do (Kim and Hammoudeh, 2013). However, the negative changes in this oil price cause changes in the stock prices for only Morocco, Oman, 
and Saudi Arabia. As indicated earlier, Morocco is not an oil producer, while Oman and Saudi Arabia have strong dependency on oil revenues.

Overall, our results reinforce the related literature in showing that oil prices and stock markets rather interact in a nonlinear manner. We further find ample evidence to support the hypotheses that the signs of changes in the causing variables are important for detecting the true causality links behind the underlying causality dynamics of the variables. However, the extent to which negative and positive changes in oil returns (stock market returns) affect stock market returns (oil returns) is not similar across the countries we consider. Comparably, while the evidence of the nonlinear causality between oil prices and MENA stock markets does not differ much according to the oil prices used, it is more pronounced in the case of the Brent oil prices. This is due to the fact that oil prices in this region are benchmarked more to Brent and WTI prices. Finally, nonlinear and asymmetric interactions between oil and stock market returns are generally more important for countries with high degree of oil dependence as well as for countries with large and liquid stock markets (Table 1).

\section{Conclusion}

WTI and Brent oil prices are important metrics to the economies and financial markets of the countries in the MENA region because the latter houses major oil producers in OPEC. Overall, the MENA countries, whether oil producers or consumers, benefit from oil revenues because of cross market investments and financial assistance. Thus, studying the causal relationships between the MENA stock markets and oil prices is of particular interest for investors and policymakers in this region. Given the changes in the global markets due to the 20072009 global financial crisis and the particular nature of the oil markets, this article focuses on the MENA markets during this particular rare period (Khalifa et al., 2013).

To the extent that the nonlinear behavior in oil and stock prices in response to shocks arising from exogenous geopolitical events, supply interruptions and unexpected crises is now 
gaining prominence in the energy finance literature, this study focuses in particular on the nonlinear Granger causality between major global oil prices and each of the eleven MENA stock markets during and after the global financial crisis. The nonlinear Kyrtsou and Labys (2006) which relies on the bivariate noisy Mackey-Glass is more appropriate than a simple VAR that is used within the standard (linear) causality framework, particularly when the dependency structures of the time series under consideration are more complicated.

Using the daily data for eleven MENA markets over the period from July 2, 2007 to August 27, 2012, our results show more conformity with the nonlinear causality relationships than with the linear relationships, particularly due to the fact the nonlinear relationship captures the financial stresses during the recent financial crisis better than the linear causality. We also find strong evidence to provide support to the asymmetry hypothesis that the signs of changes in the causing variables which are the oil prices are significant for detecting the true causality links behind the underlying nonlinear causality dynamics for MENA stock returns. The signs of changes in the oil prices affect most MENA stock markets but differently. Positive changes affect the market returns of Jordan, Qatar and Saudi Arabia, while negative changes cause stock return movements in Morocco, Oman, and Saudi Arabia. Obviously, the Saudi Arabian stock market shows nonlinear sensitivity to both positive and negative changes in the oil prices, while the non-oil producers (Jordan and Morocco) respond differently to positive and negative changes in oil prices. This implies that decision makers should respond asymmetrically to increases and decreases in oil prices in those countries. Moreover, model builders should construct nonlinear models that accommodate asymmetry in the oil markets. 


\section{References}

Aloui, C., Nguyen, D.K., Njeh, H., 2012. Assessing the impacts of oil price fluctuations on stock returns in emerging markets. Economic Modelling 29, 2686-2695.

Basher, S.A., Sadorsky, P., 2006. Oil price risk and emerging stock markets. Global Finance Journal 17, 224-251.

Choi, K., Hammoudeh, S., 2006. Behavior of GCC stock markets and impacts of US oil and financial markets. Research in International Business and Finance 20, 22-44.

Ciner, C., 2001. Energy shocks and financial markets: nonlinear linkages. Studies in Nonlinear Dynamics and Econometrics 5, 203-212

Driesprong, G., Jacobsen, B., Benjiman, M., 2008. Striking oil: Another puzzle? Journal of Financial Economics 89, 307-327.

El-Sharif, I., Brown, D., Burton, B., Nixon, B., Russell, A., 2005. Evidence on the nature and extent of the relationship between oil prices and equity values in the UK. Energy Economics 27, 819-830.

Granger, C.W.J., 1969. Investigating causal relations by econometric models and cross spectral methods. Econometrica 37, 424-438.

Granger, C.W.J., Newbold, P., 1986. Forecasting Economic Time Series. Academic Press, 2ed.

Hamilton, J.D., 2003. What is an oil shock? Journal of Econometrics, 113, 363-398.

Hammoudeh, S., Nandha, M., 2007. Systematic risk, and oil price and exchange rate sensitivities in Asia-pacific stock markets. Research in International Business and Finance 21, 326341.

Hristu-Varsakelis, D., Kyrtsou, C., 2008. Evidence for nonlinear asymmetric causality in US inflation, metal, and stock returns. Discrete Dynamics in Nature and Society, http://dx.doi.org/10.1155/2008/138547 (7 pages).

Huang, R.D., Masulis, R.W., Stoll, H.R., 1996. Energy shocks and financial markets. Journal of Futures Markets 16, 1-27.

Jammazi, R., Aloui, C., 2010. Wavelet decomposition and regime shifts: assessing the effects of crude oil shocks on stock market returns. Energy Policy 38, 1415-1435.

Jawadi, F., Arouri, M., Bellalah, M., 2010. Nonlinear linkages between oil and stock markets in developed and emerging countries. International Journal of Business 15, 19-31.

Jones, C.M., Kaul, G., 1996. Oil and the stock markets. Journal of Finance 51, 463-491

Khalifa, A., Hammoudeh, S., Otrano, E., 2013. Patterns of volatility transmissions within regime switching across GCC and global markets. International Review of Economics and Finance, In Press.

Kim, W.J., Hammoudeh, S., 2013. Impacts of global and domestic shocks on inflation and economic growth for actual and potential GCC member countries. International Review of Economics and Finance 27, 298-317.

Kyrtsou, C., Labys, W.C., 2006. Evidence for chaotic dependence between US inflation and commodity prices. Journal of Macroeconomics 28, 256-266.

Lardic, S., Mignon, V., 2008. Oil prices and economic activity: An asymmetric cointegration approach. Energy Economics 30, 847-855. 
Mackey, M.C., Glass, L., 1977. Oscillations and chaos in physiological control systems. Science 197, 287-289.

Maghyereh, A., Al-Kandari, A., 2007. Oil prices and stock markets in GCC countries: new evidence from nonlinear cointegration analysis. Managerial Finance 33, 449-460.

Miller, J.I., Ratti, R.A., 2009. Crude oil and stock markets: Stability, instability, and bubbles. Energy Economics 31, 559-568.

Narayan, P.K., Narayan, S., 2010. Modelling the impact of oil prices on Vietnam's stock prices. Applied Energy 87, 356-361.

Ono, S., 2011. Oil price shocks and stock markets in BRICs. European Journal of Comparative Economics 8, 29-45.

Papapetrou, E., 2001. Oil price shocks, stock market, economic activity and employment in Greece. Energy Economics 23, 511-532.

Sadorsky, P., 1999. Oil price shocks and stock market activity. Energy Economics 21, 449469 